\title{
Should I stay or should I go? Exit Options within Mixed Systems of Public and Private Health Care Finance
}

\author{
Neil Buckley ${ }^{\mathrm{a}}$, Katherine Cuff ${ }^{\mathrm{b}}$, Jeremiah Hurley ${ }^{1, b, c}$, Stuart Mestelman ${ }^{\mathrm{b}}$, \\ Stephanie Thomas ${ }^{\mathrm{b}}$, and David Cameron ${ }^{\mathrm{b}, \mathrm{c}}$ \\ ${ }^{a}$ Department of Economics, York University, 4700 Keele Street, Toronto, ON, Canada, M3J 1P3 \\ ${ }^{\mathrm{b}}$ Department of Economics, McMaster University, 1280 Main Street West, Hamilton, ON, \\ Canada, L8S 4M4 \\ ${ }^{\mathrm{c}}$ Centre for Health Economics and Policy Analysis, McMaster University, 1280 Main Street West, \\ Hamilton, ON, Canada, L8S 4K1
}

20 Mar 2016

${ }^{1}$ Corresponding Author: hurley@mcmaster.ca, 905-525-9140 ext. 23768 


\begin{abstract}
Mixed public-private finance is widespread in health care systems internationally. In one variant of mixed finance, some countries (e.g., Germany) allow eligible beneficiaries to fully exit from the public (social insurance) system and purchase private insurance. Using a controlled laboratory experiment, we empirically investigate the predictions of a political economy model of mixed systems of public and private finance with two types of exit: universalexit, when all individuals can choose to exit the public system, and conditional-exit, when only individuals with an income at or above a threshold income level can choose to exit. We find that high-income individuals are less likely to exit under universal-exit than under conditional-exit, despite having the same incentive to exit in both treatments. Sensitivity treatments suggests that a number of factors may be at play in explaining this result, including learning effects, a priming effect and a framing effect, but that other-regarding preferences do not appear to be an important factor.
\end{abstract}

Key Words: health care financing, publicly provided private good, mixed financing, voting experiment, framing effect

JEL: I1, H42, H44, C91, D7

Acknowledgments: We would like to acknowledge helpful comments received from three anonymous referees; participants in the 1st Behavioural and Experimental Economics Workshop, Oslo; the 9th World Congress of the International Health Economics Association, Sydney; and the 46th (Calgary) and 47th (Montreal) Annual meetings of the Canadian Economics Association. We acknowledge funding support from the Canadian Social Sciences and Humanities Research Council. (\#410-2011-2110) 


\section{Introduction}

Mixed public and private finance is widespread in health systems internationally. Public finance predominates in most countries (even in the US if tax expenditures associated with the tax treatment of private health care insurance are included), while private finance plays a variety of (often controversial) roles that depend on the design of the financing system. Private finance can complement or substitute for public finance. Complementary private finance arises in all countries and includes, for instance, private insurance for services not covered by the public plan or private purchases to "top-up" public coverage (e.g., privately purchasing physiotherapy visits or home care beyond the amount covered by the public plan). Private finance as a substitute for public finance take two basic forms: "opt-out," whereby an individual purchases duplicate private insurance for publicly insured services while still contributing taxes to support the public system, and "exit," whereby an individual wholly withdraws from the public system, forfeiting both the right to obtain public care and the obligation to contribute to financing the public plan. Opting-out is allowed in most countries and plays a large role in countries such as Australia, Portugal, Spain, and Ireland. Exit is less common, but played a prominent role in the Netherlands prior to its 2006 reforms, is a prominent feature of the German system of health care financing, and plays a smaller role in countries such as Austria. Germany and Austria provide a conditional-exit option: only those individuals who satisfy specified conditions can choose to exit, though the conditions differ by country. Germany specifies an income condition whereby only those with an annual income greater than the specified threshold (€54,900 in 2015) are eligible to exit the public system. In contrast, Austria specifies an occupation-based condition whereby only certain self-employed professionals are eligible to exit.

Mixed systems of public and private finance characterized by one or more of top-up, optout or exit are not unique to health care. They also exist for other publicly provided private goods such as education, social services and garbage collection. For this reason, they have been the focus of considerable theoretical analysis and, increasingly, empirical investigation (e.g., Cohen-Zada and Justman 2003; Bearse et al. 2013). The standard theoretical political economy models (e.g., Stiglitz 1974; Epple and Romano 1996a, 1996b; Gouveia 1997; Glomm and Ravikumar 1998) focus on only two types of private finance options noted above - top-up 
and opt-out - both of which require individuals to continue to finance public provision of the good even while privately topping up or opting out. More recently, Myers and Lülfesmann (2009) consider the case in which any household, regardless of income, can choose to exit the public system. Such an option can be characterized as universal-exit. Such theoretical models provide valuable insight into outcomes under mixed systems of finance, but given the controversy regarding mixed public and private finance in sectors such as health care, it is important to empirically test the predictions of these models.

In this paper, we modify the political economy models of mixed financing of private goods to allow for either a universal-exit option or a conditional-exit option and use controlled laboratory experiments to empirically investigate the predictions of these two exit models. Our objectives are to test the predictions of these political economy models in a controlled laboratory environment, including both non-health and health frames and, based on the observed outcomes, draw implications for mixed systems of health care finance.

In the standard top-up and opt-out models, uniform public provision of a private good is financed with a proportional income tax. Individuals first vote on the proportional tax rate, which establishes the level of public provision of the good, and then decide whether and how much of the good to purchase privately in addition to, or in place of, the public provision. Regardless of their private purchases decision, individuals continue to finance public provision. Buckley et al. (2015) investigate the behavioral predictions of such top-up and opt-out models. This paper extends this previous work to consider an environment in which individuals can exit the public system, withdrawing their financial contributions while obtaining the good privately. Allowing for a universal-exit option is predicted to result in a complete unraveling of the public system as all individuals, save the lowest income individual, will have incentive to exit. Under conditional-exit, which limits the exit option to high-income individuals only, those with high incomes are predicted to exit and consequently the per-capita level of public provision will be below that provided in the absence of an exit option.

To test these theoretical predictions of mixed systems of finance with exit options, we use controlled laboratory experiments. Laboratory experiments are well suited for empirically testing predictions of such models, and are especially important given that observational 
data are often either not available or are ill-suited for such testing. While our baseline experiment uses a neutral investment decision-making context, we also provide a sensitivity analysis comparing these experimental results to sessions run with an explicit health care frame. ${ }^{1}$ Our experiments include three financing configurations: public-finance-only, mixed financing with universal-exit, and mixed financing with conditional-exit. The design uses a combination of within-subject and between-subject designs. All subjects experience a baseline treatment of ten periods of a public-only financing system, followed by ten periods in one of the two mixed systems with exit (universal-exit or conditional-exit). Comparison of the baseline public-finance-only scheme and each of the two mixed financing schemes relies on within-subject variation, while the comparison of the two mixed financing schemes relies on between-subject variation. Any ordering/persistence effect is addressed by reversing the ordering of the public-only and mixed financing (with exit) treatment pairings so that half the subjects experience the mixed financing system first, followed by the public-finance-only treatment. In each decision period of all treatments individuals are assigned an exogenous income. In the public-only treatment individuals must choose their preferred proportional income tax rate. In the exit treatments individuals who are permitted to exit must choose whether to exit. If they choose to exit, they then have to choose the amount of the private good they will consume. All individuals who do not exit (either by choice or design) must choose their preferred proportional income tax rates. The proportional tax rate used to finance the public provision of the private good is determined by the median tax rate among the preferred rates submitted by the participants in a laboratory session. This captures the outcome of commonplace majority-rule voting due to the median voter theorem, which states that when individuals have single-peaked preferences a majority-rule voting system will result in the outcome most preferred by the median voter (Black, 1948).

The experimental results reveal some noteworthy differences in behavior under the different exit options. First, we find that in the conditional-exit treatment both the exit behavior of high-income individuals and the tax rates selected by those who remain in the public system are consistent with the theoretical predictions. In the universal-exit treatment, however, high-income individuals are less likely to exit than predicted by theory and consequently,

\footnotetext{
${ }^{1}$ Ahlert, Felder, and Vogt (2012) and Kesternich, Schumacher, and Winter (2015) also investigate health versus neutral framing of experiments, although neither study focuses on health care finance.
} 
more people contribute to public provision of the private good than is predicted. Even though the incentives for high-income individuals to exit are identical under both the universal and income-conditional schemes, high-income individuals are less likely to exit when the exit option is universal. Making exit conditional on high-income appears to give the high-income individuals "permission" to exit. Attempts to identify the source of differences in behavior by high-income individuals under the two schemes suggest that a number of factors may be at play including learning effects and a type of priming effect, but other-regarding preferences do not appear to be an important factor. Also, tax- and exit-rate decisions are found to be more consistent with the theoretical predictions when the decision-making environment is framed in terms of health care rather than a neutral investment decision.

In the next section, we outline our theoretical framework. In Section 3, we describe the laboratory implementation of the theoretical framework and present our main experimental results in Section 4. We then discuss subjects' observed exit behavior in Section 5 and present results on health care framing effects in Section 6. Finally, we conclude in Section 7.

\section{Theoretical Framework}

We develop a simple discrete version of a commonly used majority-rule voting model of tax-financed public provision of a private good (see e.g., Glomm et al. 2011) that allows for an exit option. ${ }^{2}$ There are $N$ individuals or households who differ in their fixed income (or endowment of a numeraire consumption good) denoted by $y$. The mean income in the population is $\bar{y}$, the median income, $y_{m}$, and the median is assumed to be less than the mean. Households have preferences over consumption of a numeraire good, given by $c$, and of a specific private good that may be publicly provided or purchased privately, given by $H$. Household preferences are represented by the following utility function: ${ }^{3}$

$$
U(c, H)=a c^{\eta}+b H^{\eta}
$$

\footnotetext{
${ }^{2}$ These standard political economy models typically assume a continuous population distribution and general individual preferences. To implement the theoretical environment in a laboratory setting we adopt a discrete income distribution and a specific utility function to obtain closed-form solutions.

${ }^{3}$ The specific utility function and the assumed parameter values we use are based on Buckley et al. (2015).
} 
where $a, b>0$ and $\eta \in(0,1)$. The private good $H$ is produced using the numeraire good. Following the literature, it takes one unit of the numeraire good to produce one unit of $H$ independent of whether $H$ is publicly or privately financed.

Consider first the decision of a household who chooses to exit the public system. Because the household is not financing the public provision of the private good and is financing its own consumption of the private good, the household maximizes (1) subject to the following budget constraint ${ }^{4}$

$$
c+h=y
$$

where $h$ denotes the amount of $H$ purchased privately. This problem yields the household's optimal demand for the private good

$$
h(y)=\frac{y}{\phi+1}
$$

where $\phi=(a / b)^{\frac{1}{1-\eta}}>0$ and $h^{\prime}(y)>0$.

Theoretical Prediction 1 For households that choose to exit the public system, their optimal purchases of the private good will be given by (3) and will be increasing in their income.

Next we characterize the public system and exit behavior in each of the three treatments we consider: public finance only, mixed financing with a universal-exit option, and mixed financing with a conditional-exit option.

\subsection{Public Finance Only}

In a public-only finance system, the provision of $H$ is financed solely through a proportional income tax, denoted by $t$ which is determined by majority-rule. The government provides a uniform amount of the private good, denoted by $g_{H}$, to each household. The government's budget constraint is

$$
t \bar{y}=g_{H}
$$

\footnotetext{
${ }^{4}$ The household's problem is well-behaved.
} 
Using the government's budget constraint (4), the household's budget constraint can be written as

$$
c=y-(y / \bar{y}) g_{H}
$$

where $T(y)=y / \bar{y}$ is the household's relative tax price for the private good.

Substituting the household's budget constraint (5) into (1) with $H=g_{H}$, yields the household's induced utility function over the public provision of the private good

$$
V(g) \equiv \max _{g_{H} \geq 0} a\left(y-T(y) g_{H}\right)^{\eta}+b g_{H}^{\eta}
$$

which is strictly concave in $g_{H}$. Therefore, each household has a unique preferred level of public provision, denoted by $g_{H}(y)$, and a unique preferred tax rate, denoted by $t(y)$, which are both strictly decreasing in household income. It follows directly from the median voter theorem that the equilibrium outcome under majority rule will be given by the preferred tax rate of the median income household

$$
t\left(y_{m}\right)=\frac{1}{\phi T\left(y_{m}\right)^{\frac{\eta}{1-\eta}}+1} .
$$

The amount of public provision in equilibrium will be

$$
g_{H}\left(y_{m}\right)=\frac{y_{m}}{\phi T\left(y_{m}\right)^{\frac{1}{1-\eta}}+T\left(y_{m}\right)} .
$$

Theoretical Prediction 2 In a public-only financing system, preferred tax rates are strictly decreasing in income and the equilibrium outcome with majority-rule will be determined by the preferred tax rate of the median-income household.

In a public-only financing system, all households receive the same amount of $H$, but face different relative tax prices for the private good that are increasing in income. The household with the mean income faces the same price for the private good whether the good is financed publicly or privately. Consequently, public provision of the good effectively redistributes resources from households with incomes above the mean (who face higher relative tax prices) to households with incomes below the mean (who face lower relative tax prices).

Now consider what happens to the public provision of the private good when households 
can choose to not pay taxes to finance the public provision of $H$, and instead purchase $H$ privately. We consider two cases: universal-exit and conditional-exit.

\subsection{Mixed Financing: Universal-Exit Option}

Consider first the universal-exit option in which all households can choose to exit. A household who exits the public system pays no taxes to support public provision and has its full income available when choosing how much of $H$ to purchase privately. The timing of this treatment is as follows:

1. Households decide whether to exit the public system. Households who choose not to exit the public system vote on the level of public provision, i.e., vote on the proportional income tax to be applied to all those households who remain in the public system. The voting outcome is determined by majority rule.

2. Households who exit choose how much $H$ to purchase privately.

Only households who have chosen to remain in the public system are allowed to vote for the public tax rate. ${ }^{5}$ Since households who exit do not pay any taxes, they should be indifferent across all possible tax rates. Allowing these households to vote on the tax rate could result in a situation in which a majority-preferred tax rate does not reflect the preferences of the households that remain in the public system, to which the tax rate applies. Second, households vote on the tax rate before knowing which households have exited; that is, households play a simultaneous-move game.

Public provision redistributes income from high- to low-income households. Therefore, the highest-income household is worse off in a public system than in a private-finance only system. Hence, the highest-income household has a strictly dominant strategy to exit. Consider the next highest income household. Recognizing that the highest-income household will exit, this household now also has a strictly dominant strategy to exit the public system. By the continued iterated deletion of strictly dominated strategies, all households, except

\footnotetext{
${ }^{5} \mathrm{An}$ example of a situation in which those who exit are removed from voting is provided by the Canada Elections Act, which currently prohibits Canadian citizens who have lived abroad for more than five years from participating in Canadian federal elections.
} 
the household with the lowest income (denoted by $y_{\min }$ ), will choose to exit the public system. The lowest-income household will be indifferent between exiting or not since a public system with only one household is equivalent to a private-finance only system. The amount of private good consumed by each household will be given by (3). Allowing for universal-exit is predicted to result in a system of private-finance only.

Theoretical Prediction 3 In a mixed financing system with an universal-exit option, all households will choose to exit except the lowest-income household, who will be indifferent between exiting and not exiting.

\subsection{Mixed Financing: Conditional-Exit Option}

Consider a conditional-exit option that allows a household to exit the public system only if the household's income is above a specified income threshold. The timing of the exit decision is the same as in the universal-exit treatment, but only those with incomes above the threshold can choose to exit. It is straightforward to see that again by iterated deletion of dominated strategies all households with incomes at or above the threshold will optimally exit. The public system will consist of all households with incomes below the threshold income level, denoted by $\hat{N}<N$, and the analysis of this public system is the same as the one described in section 2.1 with $N$ replaced by $\hat{N}$. Again, privately purchased amounts of $H$ by those who exit the public system are given by (3).

Theoretical Prediction 4 In a mixed financing system with an income-conditioned exit option, all those households with income above the income threshold will exit the public system. The equilibrium tax rate in the public system will be determined by the preferred tax rate of the household with the median income among those households remaining in the public system.

In summary, under public-only finance all individuals will be in the public system, under universal-exit there is predicted to be only private provision and under conditional-exit highincome individuals are predicted to be in the private system and low-income individuals are predicted to be in the public system. Thus, the alternative systems of finance considered are expected to give rise to differing demands for $H$. In Section 5, we discuss the predicted total demand for $H$ under the different financing systems given the specific parameter values we 
implement in the experiment. ${ }^{6}$

\section{Laboratory Implementation}

We use a controlled laboratory experiment to test the above theoretical predictions regarding the equilibrium outcomes of majority-rule voting over the tax-financed public provision of a private good under public-only financing and mixed financing with either a universalexit option or with a conditional-exit option. Following standard experimental economic methodology, household or individual decision-makers, i.e., subjects, in the experiment are incentivized with real monetary payoffs. The main experiment is framed in an investment context to reflect the neutral consumption setting of the theoretical models of public provision of private goods and a context that is commonly used in the experimental economics literature (Alm and Jacobson 2007). Subject decisions are framed as choices over how much to invest in alternative investment funds, including a collective group fund and an individual private fund. We recognize that a decision made between an individual fund and a group fund is not strictly neutral (Dufwenberg et al., 2011), but this terminology is used to facilitate subject comprehension of the decision-making environment. The impact of a neutral investment frame rather than a health care frame is tested by comparing results from the neutral investment frame sessions with results from sessions that use an explicit health care frame. This sensitivity analysis is presented in Section 6 below. The complete set of instructions used in the experiment can be found in the Appendix.

Each session was run with ten subjects who were told that they would be randomly assigned to be a member of a group of five people, but were not told who was in their group. Each group remained together through the session (following Buckley et al., 2015, Kroll et al., 2007 and Margrieter et al., 2005) so that the two groups in each session represented independent observations. Subjects were told that, at the beginning of each decision period, each member of their group would randomly be assigned an income, expressed in laboratory dollars (L\$), from the following set of five income levels $(125,275,640,700,1500)$, and that

\footnotetext{
${ }^{6}$ Following the literature we assume that provision of $H$ is subject to constant marginal costs. This assumption could be relaxed to incorporate increasing marginal costs provided that preferences remain single-peaked in public provision and preferred public provision is decreasing in income. Total demand for $\mathrm{H}$ under the different financing systems would then be affected by the assumed underlying cost function.
} 
each individual would be assigned each of the income levels twice over the course of the ten periods of the treatment. The income distribution was chosen to ensure that the median income was below the mean (consistent with the theoretical assumption). ${ }^{7}$ To keep subjects actively thinking about their decisions, incomes were assigned in a pre-determined pseudorandom order such that in each treatment subjects experienced each of the five income levels in the first five periods and then again in the last five periods, but in a different order. The effect of randomizing incomes is tested below in Section 5, which presents results from sessions in which each subject's income was held fixed over the entire session.

As noted earlier, the experiment used a combination of within-subject and betweensubject designs. All subjects experienced ten decision periods of a public-only financing treatment and ten decision periods of one of the two mixed financing systems, where the order of the two treatments (public/mixed) was randomized across experimental sessions to control for potential order effects. Comparison of the baseline public-only financing system and the two mixed financing systems relies on within-subject variation, while the comparison of the two mixed financing systems (universal-exit and conditional-exit) relies on betweensubject variation.

At the beginning of each decision period of the public-only finance treatment, subjects were told that their income must be divided between two Investment Funds: a Group Investment Fund (GIF) and a Private Investment Fund (PIF). Subjects were told that everyone in their group must contribute the same fixed percentage of their income to the GIF and that this percentage would be determined by the group. The total amount contributed to the GIF would be divided into five equal shares. Each share would be invested in Market A and the subject would earn a return from this investment. The subject's remaining income after contributing to the GIF would go into the subject's PIF and be invested in Market B where it would earn a return for the subject. The returns earned on the investments were calculated using the payoff function given by (1), where the GIF investment in Market A is for the private good $H$ and the PIF investment in Market B is for the numeraire good $c$ with the following parameter values: $a=20, b=22$ and $\eta=0.6 .^{8}$

\footnotetext{
${ }^{7}$ This distribution of income is roughly representative of the incomes at the 10th, 30th, 50th, 70th and 90th percentiles in Canada in 2013.

${ }^{8}$ These parameter values were chosen to assure the saliency of subject decisions in the experiment and are based on values used by Buckley et al. (2015).
} 
In each of the decision periods of the public-only treatment, subjects were asked to submit their preferred mandatory GIF contribution rate. To replicate the outcome of majority-rule voting in a laboratory environment, subjects were told that the submitted GIF contribution rates would be ranked from highest to lowest and that the median contribution rate would be implemented. ${ }^{9}$ It was explained to them why there was no incentive to submit a contribution rate other than their preferred rate. Subjects were provided with tables and tutorial examples to illustrate how the returns worked in the markets and an onscreen calculator that allowed them to determine their returns in both markets as well as their total return for different income levels and different GIF contribution rates. Subjects were able to access the calculator throughout the session.

In the universal-exit treatment, subjects were provided the same information as in the public-only treatment as described above, but were also told that they could decide whether or not to participate in the group investment fund. Subjects were told that if they choose not to participate in the GIF, then they would not make any contribution to the GIF and would not receive any share of the GIF. The subjects would, however, be able to choose how much of their income to invest in a different market, Market $\mathrm{C}$, where the returns to investment in Market $\mathrm{C}$ are the same as in Market A. Whatever amount not invested in Market C, would then be automatically invested in Market B on behalf of the subject. The subjects' total returns for each period if they choose not to participate in the GIF is the sum of the returns of their investments in Markets B and C. Subjects were told that if they choose not to exit, everyone who remained in the GIF would be asked to submit their preferred GIF contribution rates. The submitted GIF contribution rates would be ranked from highest to lowest. In the case of an odd number of subjects remaining in the GIF, the middle-ranked contribution rate would be implemented. In the case of an even number of subjects remaining in the GIF one of the two middle-ranked submitted GIF rates would be randomly chosen and implemented.

\footnotetext{
${ }^{9}$ Differing voting processes have been implemented experimentally. The seminal work by Fiorino and Plott (1978) uses a sequential amendment-driven voting protocol while more recent papers use either simultaneous voting protocols (e.g., Margreiter et al. 2005; Kroll et al. 2007) or a binary yes/no vote on a given tax proposal (e.g. Sutter and Weck-Hannemann 2003). Another approach is to allow each individual to propose a tax rate and to implement the median tax rate (e.g. Buckley et al., 2015; Norton and Isaac, 2013). We adopt the latter voting process since it most closely resembles the theoretical environment that was being implemented in the lab.
} 
The conditional-exit treatment was described similarly to the universal-exit treatment except only subjects with the two highest income levels $(700,1500)$ were given the choice of participating in or exiting from the GIF. Subjects with incomes of 125, 275 and 640 automatically remained in the GIF. At the end of each of the ten periods of both exit treatments, all subjects were told the total number of subjects who participated in the GIF, the implemented GIF contribution rate, the total amount contributed to the GIF, their own investments and returns in Markets A and B (if the subjects participated in the GIF) or in Markets $\mathrm{C}$ and $\mathrm{B}$ (if the subjects did not participate in the GIF) and finally their own total returns for the period.

In both exit treatments, each subject was provided with examples to illustrate how her returns were determined depending on which subjects participated in the GIF, including the cases when all subjects participated in the GIF, the subject remained in the GIF but other subjects exited, and when the subject herself exited the GIF. Subjects were also given a tutorial in the use of an onscreen calculator that allowed them to determine their total returns for different income levels, GIF contribution rates, and different exit decisions made by themselves and others. Subjects were given a few minutes to practice using the calculator and were able to access the calculator whenever they were asked to make a decision.

All subjects were recruited using an online recruitment system for controlled laboratory experiments (ORSEE, Greiner 2015) and the experiment was administered in the McMaster Experimental Economics Laboratory. Our main experimental design involves five groups of five subjects each experiencing one of the following treatment pairs: public-only followed by universal-exit, universal-exit followed by public-only, public-only followed by conditionalexit and conditional-exit followed by public-only. Additional treatments were also run as part of a sensitivity analysis. Each session had twenty decision periods (ten decision periods for each treatment) and lasted approximately 70 minutes. ${ }^{10}$ The average subject payoff was $\$ 23$ including a $\$ 5$ show-up fee. Subjects were individually paid their cash earnings in private. The experiment was conducted using z-Tree software (Fischbacher 2007) and the laboratory protocol was approved by the McMaster University Research Ethics Board. Table

\footnotetext{
${ }^{10}$ All treatments used a repeated game design for the 20 periods, so decisions made in any one period did not have consequences for other periods. For example, if a subject exited in period 12, in period 13 they faced a new decision whether to exit.
} 
1 summarizes the experimental design for all treatments presented below.

\section{Experimental Results}

We begin by testing for learning effects between the first five decision periods and the second five decision periods of the main design presented in Table 1 with respect to the mean implemented GIF rate (hereafter referred to as the tax rate), the subjects' mean exit decisions and the mean private purchases of those who choose to exit for each ordering of the treatments: public-only followed by one of the two exit treatments and one of the two exit treatments followed by the public-only treatment. There is evidence of marginal learning effects with respect to the mean implemented GIF rate when the universal-exit treatment was experienced first. ${ }^{11}$ We next test for order effects to determine if there are any differences in the mean implemented GIF rates, mean exit decisions, and mean private purchases depending on whether the universal-exit treatment or the conditional-exit treatment appears first or second in the session. Our tests show no evidence of order effects. ${ }^{12}$ For the analysis presented below we focus on the last five decision periods of each treatment to account for any marginal learning effects.

We create an independent observation for each group of five subjects in each session of each treatment by computing the mean value across the last five decision periods for each of the mean implemented tax rate, mean exit decisions and mean private purchases. Because there are no order effects, this provides 10 independent observations of each variable for the following treatments: public-only (paired with universal-exit), public-only (paired with conditional-exit), universal-exit and conditional-exit. Any differences from null hypotheses are judged statistically significant if the p-value is not greater than the significance level

\footnotetext{
${ }^{11}$ As the same subjects make decisions in both the first- and second-half of each treatment, we use a non-parametric Wilcoxon Signed Rank test to obtain five independent observations for each treatment. We cannot reject the null hypotheses that there are no differences in the mean implemented GIF rates, subjects' mean exit decisions or mean private purchases of those who choose to exit between the first five and the last five periods of each treatment when the public-finance-only treatment was seen first. We also conducted parametric paired t-tests and found similar results. Comparisons between within-subject treatments reported in subsections 4.1 to 4.6 below also use these same non-parametric and parametric significance tests.

${ }^{12}$ Because ordering of treatments was varied between subjects, the mean observations are independent; we therefore test for order effects using both Mann-Whitney and Fisher-Pitman Randomization nonparametric tests (Moir, 1998). The p-values are all above 0.10 and we cannot reject the null hypotheses of no differences in these mean outcomes across the three treatments. These results are also supported by parametric t-tests.
} 
of 0.10. All hypothesis tests are conducted using parametric paired or unpaired t-tests (as appropriate) and non-parametric Mann-Whitney or Wilcoxon Signed-Ranks tests (as appropriate). We only identify the specific tests that are used if there is a difference between the results using parametric and non-parametric tests.

\subsection{Exit Decisions}

Exit behavior differed substantially between the universal-exit and conditional-exit treatments as shown in Tables 2 and 3. The rates of exit in the universal-exit treatment were notably lower than predicted for all income levels, although, as expected, they were increasing in income. In contrast, in the conditional-exit treatment although exit rates of 0.940 for individuals with incomes of 700 and 1500 are statistically significantly different from a rate of 1.000, they are quite close to the predicted value of 1.0.

In the conditional-exit treatment individuals with the two highest incomes appear to have understood the benefit to them of exiting; in the universal-exit treatment, however, either they did not have this same degree of understanding or, if they did, they chose not to act on it, because individuals with incomes of 700 and 1500 had exit rates of 0.720 and 0.760 respectively. Further, given that higher-income individuals did not exit as expected, lowerincome individuals had an incentive to remain in the public system because they receive income transfers from the higher-income individuals through the public provision of the private good. Hence, their exit rates are low and the public system does not unravel as predicted for the universal-exit treatment.

Result 1 Participants in the conditional-exit treatment exited as predicted but participants in the universal-exit treatment exited less often than predicted, with higher-income individuals exiting more frequently than lower-income individuals.

\subsection{Private-Purchase Decisions}

As also shown in Tables 2 and 3, the average amounts of private purchases made by subjects who chose to exit in the universal-exit treatment track the predicted values quite well, and none of the differences are statistically different. There is, however, a tendency for lower- 
income individuals to over-invest (by 17 and 11 percent for individuals with incomes 125 and 275 respectfully) and for higher-income individuals to under-invest (by 5 percent for individuals with incomes 700 and 1500). For the conditional-exit treatment, individuals with incomes of 700 or 1500 who choose to exit invest about nine percent less than predicted.

Result 2 In both of the universal- and conditional-exit treatments the private purchases by those individuals who chose to exit are close to the amounts predicted by the theoretical model.

\subsection{Mean Preferred Tax Rates}

Table 4 presents a comparison, by income, of the observed mean preferred (i.e., submitted) tax rates and the theoretically predicted values. ${ }^{13}$ In the public-only treatment the observed mean preferred tax rates are decreasing in income (as predicted), but they are slightly less (by less than ten percent) than predicted for incomes 125, 275, 640 and 700 and slightly greater (by less than ten percent) than predicted for individuals with income of $1500 .{ }^{14}$

Because the model for the universal-exit treatment predicts that individuals with income greater than 125 will exit, there are no predicted tax rates for the universal-exit treatment, except for the lowest-income subjects, who prefer a tax rate of 0.559 if they remain in the public system. Many of the lowest-income subjects did remain in the public-system and their mean submitted rate was substantially higher than the predicted value. This is not surprising given that those with greater incomes chose not to exit and the preferred rate is greater than 0.559 for those with income of 125 when higher-income individuals do not exit. Analogously, the mean preferred rates reported by individuals with incomes of 275 and 640 are between the rates predicted for the public-only and conditional-exit treatments, which is consistent with an environment in which individuals with incomes of 700 and 1500 frequently do not exit from the public system (which occurs more than a quarter of the time in the universal-exit treatment). Overall, the behavior of participants in the universal-exit treatment is not consistent with the theoretical predictions.

In the conditional-exit treatment, the mean preferred rates reported by the three lowest

\footnotetext{
${ }^{13}$ Statistical tests between each exit treatment and public-only finance used solely public-only data from the paired public-only treatment.

${ }^{14}$ These comparisons pool the public-only data across the twenty groups.
} 
income subjects, who must remain in the public system, differ from the predicted values by $-0.033,0.018$ and 0.047 , respectively. These differences are statistically significant for incomes 125 and 640. However, for those with income of 275 (the median voter) the mean preferred tax rate does not differ statistically from the predicted rate, which reflects in part the fact that subjects with incomes of 700 and 1500 exit (as predicted) more than ninety percent of the time. ${ }^{15}$

Result 3 The mean preferred tax rates for individuals in the public-only and conditional-exit treatments are not substantially different from the rates predicted by the underlying theoretical model. The data generated by the individuals in the universal-exit treatment do not support the predictions of the theoretical model.

\subsection{Mean Implemented Tax Rates}

We now compare the observed mean implemented tax rates against the theoretically predicted values for each of the three treatments as shown in Table 5. The predicted tax rate in the public-only treatment is 0.564 and the actual mean implemented tax rates in the publiconly treatments (when paired with either exit treatment) do not differ from this prediction. In addition, the actual mean implemented tax rate in the conditional-exit treatment did not differ from its predicted tax rate. In the universal-exit treatment, when all subjects can choose to exit, there is no prediction for the tax rate as all subjects, save the lowest income subject, are predicted to exit. If only the lowest income individual remained to participate in the public system, then the predicted tax rate is 0.559 . The actual mean implemented tax rate in universal-exit treatment differs statistically from the predicted tax rate and is consistent with an environment in which individuals with incomes greater than 125 choose to participate in the public system.

We next test for differences in mean implemented tax rates across the three treatments. There is no significant difference between the mean implemented tax rates from the public-

\footnotetext{
${ }^{15}$ Out of 100 observations of decisions made by individuals with incomes of 700 or 1500 there are only six observations (three for individuals with income of 700 and three for individuals with income of 1500) when the individual does not exit. The mean tax rates selected by the individuals with income of 700 and 1500 are 0.628 and 0.750 . Both of these are inconsistent with these individuals attempting to maximize their payoffs under any assumption of the mix of individuals who will remain in the public system.
} 
only treatments when paired with the universal-exit treatment and the public-only treatments when paired with the conditional-exit treatment, and between the universal-exit and conditional-exit treatment tax rates. However, there is a significant difference between the universal-exit and paired public-only tax rates and between the conditional-exit and paired public-only tax rates.

Result 4 The mean implemented tax rates in the public-only and conditional-exit treatments are not significantly different from the rates predicted by the underlying theoretical model. The mean implemented tax rate in the universal-exit treatment is significantly higher than predicted.

\subsection{Inequality in the Consumption of the Private Good}

Distributional concerns figure prominently in the assessment of alternative systems of health care finance. In our setting, income-related inequality in consumption (public provision plus private purchases among those who exit) is predicted to differ substantially across the three financing treatments (Table 6$).{ }^{16}$ Consumption is predicted to be equal across incomegroups under public-only financing, to exhibit a strong pro-rich gradient under universalexit, and to exhibit a stepped pro-rich pattern under conditional-exit (equal consumption among the three lower income groups and then higher consumption among the two highincome groups). We measure the extent of income-related inequality in consumption using the Concentration Index (CI), which has been applied widely within health economics to measure income-related inequalities and inequities in health, health care consumption, and health care financing (van Doorslaer and Van Ourti, 2011). The CI is directly analogous to the Gini Coefficient, but instead of measuring univariate inequality (e.g., inequality in the distribution of income in the population), it is a bi-variate measure of the extent to which inequality in a variable of interest, in this case, consumption of the private good, is systematically related to a second variable, in this case, income. The CI takes on values

\footnotetext{
${ }^{16}$ In contrast, the aggregate level of consumption is not predicted to not differ substantially across the treatments and, in fact, we find no statistical differences in observed aggregate consumption of the private good across the three treatments; nor does observed consumption differ statistically from the predicted value for the public-only and universal-exit treatments. Consumption under conditional-exit, however, is less than predicted because the high-income individuals who exit consume less privately than predicted.
} 
in the interval $[0,1]$, is zero when there is no income-related inequality, is positive when inequality favors the rich, and is negative when inequality favors the poor. Among our financing treatments, income-related inequality is predicted to be least under public-only financing and the most pro-rich under universal-exit. Because observed consumption under the public-only treatments is equal across income levels, the CIs for public-only are zero and do not differ from the predicted values. Pro-rich income-inequality in each of universaland conditional-exit is significantly different from public-only financing, and although the CI for universal-exit is less than that for conditional-exit, the difference between the two exit treatments is not statistically significant. The CI for universal-exit is significantly less than its predicted value, indicating less-than-predicted income-related inequality, due to the less-than-predicted rate of exit among high-income individuals. The CI for conditional exit is not significantly different than its predicted value.

Result 5 Pro-rich income-related inequality in consumption of the private good is substantially greater in the exit treatments than in the public-only treatment, though for the universalexit treatment the pro-rich inequality is less than predicted.

\subsection{Inequalities in Total Payoffs}

Total payoffs provide a rough measure of social welfare in our environment. The predicted total payoffs are largest for the public-only treatment and smallest for the universal-exit treatment, and, as with consumption, income-related inequality is predicted to be smallest in the public-only treatment, reflecting the redistribution that occurs under public-only financing (Table 7). As predicted, observed total payoffs are higher in the public-only treatment than in either of the two exit treatments (the difference between the exit treatments is not statistically significant). The observed total payoffs statistically differ from the predicted values only for the conditional-exit treatment, again reflecting the under-investment by the high-income subjects who exited. For all three treatments the observed CIs do not differ significantly from their predicted values. As expected, the CI for public-only financing is significantly less than that for both universal-exit and conditional-exit, although the difference between the two mixed-financing treatments is not significant.

Result 6 The level and distribution of mean total payoffs in the public-only treatment do 
not differ from the predictions, are greater than in both exit treatments, and display less income-related inequality than in both exit treatments.

\section{$5 \quad$ Why Don't Individuals Exit as Predicted?}

The difference in subject exit behavior across the two exit treatments is surprising. As noted, the two highest-income individuals in the conditional-exit treatment appeared to recognize the benefits of exiting and consequently exited at rates comparable to the theoretical predictions. However, in the universal-exit treatment individuals with the same incomes exited at rates substantially less than in conditional-exit. We offer three conjectures that might account for this difference.

First, high-income individuals in the universal-exit treatment might not exit as predicted due to altruism. Altruistic or cooperative preferences would be consistent with high-income individuals staying and supporting the public system rather than exiting if they worried that the public system would completely unravel if they exited because lower-income individuals would have the incentive to exit once the high-income individuals exit. In contrast, altruistic high-income individuals would have fewer qualms about exiting in the conditional-exit treatment knowing that middle-income individuals would have to stay and help fund the public system and provide income transfers to the lowest-income individuals.

Second, individuals in our universal-exit treatment might not exit as predicted due to a priming bias. That is, for reasons unrelated to altruistic preferences, high-income individuals may not exit as predicted if they feel that the environment into which they are placed is an environment primed with public provision. ${ }^{17}$ While the highest-income individuals may recognize the incentive to exit, they may believe that they have an obligation to help maintain this public system. This bias may not present itself in the conditional-exit treatment because high-income individuals are specifically told that they alone may exit from the public system. The conditional-exit environment grants permission for the high-income individuals to exit while requiring the middle- and low income-individuals to participate in the public system.

Third, it may take time for individuals in the universal-exit treatment to realize that the highest-income person should exit from the public system and that the natural consequence

\footnotetext{
${ }^{17}$ This priming bias is what van Dijk and Wilke (2000) call decision-induced focusing.
} 
of this is that the next-highest-income individual should then exit until the unraveling process takes place and everyone exits. This suggests that exit rates in the universal-exit treatment would be higher if it was easier for this unraveling process to take place faster.

We investigated all three of these conjectures. First, we investigated the possibility that the decision to exit from the public system may be related to the cooperativeness or altruism of the participants. Because participating in the public system results in income redistribution from high-income participants to low-income participants, the social-value orientations of the participants may be important. If our conjecture is true, the social-value orientation of subjects should be related to their exit behavior.

To explore the second, we modified our design so that subjects participated in a conditionalexit treatment for ten periods and then switched to the universal-exit treatment for another ten periods. If our conjecture is true, exposing participants first to the conditional-exit treatment will prime high-income subjects to exit more frequently in the subsequent universal-exit treatment, thereby providing greater incentive for lower-income individuals to exit.

To examine the third conjecture, we modified our design so that each subject had one of the five income levels for all decision periods (rather than experiencing all five income levels in random order), thereby giving high-income subjects greater opportunity to learn the benefits of exiting and more readily prompting the cascade of exits down the income distribution. To test this we used the design in which subjects first participated in a publiconly treatment for ten decision periods and then universal-exit treatment for another ten decision periods, but modified it so that individuals had the same income for all twenty decision-periods. In a further minor variation of this, we also ran this fixed-income design in which all subjects were told after each period which of the five subjects chose to exit, hypothesizing that explicit information about the income levels of the individuals who exit may affect exit behavior and may speed up the predicted cascade of exits.

Table 8 summarizes exit behavior for our original designs and our new sensitivity designs. Column (1) presents the mean per period exit rates by income in the original conditionalexit treatment reported in Table 3 plus the exits rates for the conditional-exit treatment that primed the universal-exit treatment run to examine the second conjecture. Column (2) presents the exit rates by income in the original universal-exit treatment reported in Table 
2. Column (3) presents the exit rates by income for the universal-exit treatment that was preceded by a conditional-exit treatment and column (4) presents the exit rates by income for the universal-exit treatment preceded by a public-only treatment but in which incomes are not randomized after each decision period. Finally, column (5) presents the design similar to that in column (4) only information about the income of the individuals who exited is also provided to everyone. Data for each of the three new designs were obtained from three sessions (i.e., nine in total), each of which included two independent groups of five subjects who were randomly assigned to groups.

To test the first conjecture, the sessions described in columns (4) and (5) were followed by a brief social-value-orientation ring game similar to those presented in Mentzakis and Mestelman (2013). ${ }^{18}$ This allowed individuals to be categorized as having altruistic, cooperative, individualistic or competitive other-regarding preferences based on their decisions in the non-strategic payoff allocation ring game. We found no evidence that individuals' exit decisions were correlated with either a continuous or categorical measure of their social value orientation.

However, the priming design had the expected effect on exit rates: comparing columns (1) and (3) reveals that high-income individuals in the universal-exit treatment that followed the conditional-exit treatment exited at rates equivalent to rates in the conditional-exit treatments and not significantly different from their predicted values. Furthermore, the higher rates of exit among high-income individuals cause the exit rates to increase among those with incomes of 125, 275 and 640. These exit rates rise from 0.080, 0.160 and 0.560 to $0.160,0.600$ and 0.800 respectively (see columns (2) and (3)), although these are still significantly below the exit prediction of 1.00. The rate of exit for all individuals who are expected to exit rises from 55 percent in the original universal-exit treatments to a significantly higher 80 percent in the primed universal-exit treatment.

Learning also appears to explain part of the low exit rate in the universal-exit treatments. A comparison of columns (2) and (4) reveals that keeping subjects' incomes constant (so high-

\footnotetext{
${ }^{18}$ While the social-value orientation game used was developed by Griesinger and Livingston (1973) and Liebrand (1984), the exact ring game used was identical to the non-incentivized social-value-orientation mechanism presented in Mentzakis and Mestelman (2013). The authors found no hypothetical bias when comparing these social-value-orientation measures to those elicited when salient monetary incentives were involved.
} 
income subjects more easily learn the benefits of exiting) also leads to higher rates of exit by high-income individuals. Further providing subjects information after each period about the incomes of those who chose to exit does not impact exit behavior as seen by comparing columns (5) and (4).

These supplemental findings indicate that the low exit rates by high-income individuals in the universal-exit treatment are not driven by other-regarding preferences, and likely derive at least in part from a bias in favor of public support that may be overcome by making it clear that exit is permitted or by providing sufficient experience in the environment so that they may learn the individual advantage of exiting. However, these factors cannot explain all of the differences observed between the universal-exit treatments, conditional-exit treatments and the theoretical predictions.

\section{$6 \quad$ Health Framing}

The results presented above are based on sessions that use an investment context, as is common in the experimental literature for fields such as environmental economics and public finance. While our theoretical model does not predict any behavioral differences between alternative frames used to give a subject context, the question of whether health care framing effects might exist in our setting is an interesting one. ${ }^{19}$ To test for possible health care framing effects, we replicated the earlier public-only, universal-exit and conditional-exit treatments using an explicit health care frame.

These health-frame sessions simply modified the language of the experimental instructions without changing the underlying decision problem of the experiment. Specifically, the investment frame terminology of a "Group Investment Fund" being invested in "Market A" was changed to a "Group Health Care Fund" being deposited into a "Health Care Account". Additionally, the terminology of a "Private Investment Fund" being invested into "Market B" was reworded to a "Private Fund" being invested into a "Private Investment Account". This modified terminology was introduced to provide subjects with a decision between an

\footnotetext{
${ }^{19}$ Harrison and List (2004) discuss the need to consider the framing context of an experiment before drawing general conclusions because without that context the experimenter is unable to control for the frames subjects impose themselves.
} 
explicitly named health care option and an explicitly named private investment option while ensuring an identical outcome and payoff situation between the two frames.

Table 9 presents the results for the exit rate, private purchase decision, and implemented tax rate for the health-frame sessions. The observed proportion of exits in the health-frame universal-exit treatment was found to be significantly higher, and closer to the predicted rate of $100 \%$, than that observed in the neutral investment treatments. Under the health frame subjects exhibited an increase in exit rates of more than 20 percentage points on average. Furthermore, implemented tax rates were found to be significantly lower in health-frame conditional-exit treatments than when neutrally framed, although on average only roughly 10 percentage points lower. However, not all relevant outcomes were found to exhibit framing effects, as implemented tax rates under the universal-exit treatment were not found to be significantly different from those found in the neutral-frame treatments; additionally, the private purchase amount of those who do exit in the health frame were also not found to be significantly different from their neutral-frame counterparts for either the universal- or conditional-exit treatments.

While the increase in exit rates under the health frame produced results more consistent with our underlying theoretical model, it is difficult to know what precisely might be driving these framing effects, beyond the fact they were induced by the framing change itself. While the decisions were framed as health-related choices, our experiment did not include any health consequences beyond those in situations in which untreated health care issues result in lost income due to an illness. This differs from both the real world, and alternative experimental designs that have been adopted in which subject decisions have real health-care related consequences for patients outside the lab (e.g., Hennig-Schmidt et al. 2011). However our framing results show that such health-care related consequences are not necessary to induce a change in behavior. Because investigating the impact of a health versus a neutral investment frame was not the primary goal of this study, we view these findings as preliminary and deserving of further investigation. 


\section{Conclusion}

This paper uses a controlled laboratory experiment to test theoretical predications regarding mixed public and private financing for a private good that allows for exit from the public system, similar to financing of health care in countries such as Germany. In such systems, individuals who choose to exit the public system neither contribute to its financing nor consume any of the publicly provided health care, but instead purchase health care privately. We investigated two exit designs: a universal-exit scheme in which everyone is eligible to exit, and a conditional-exit scheme in which only high-income individuals are eligible to exit.

Our results largely confirm the theoretical predictions regarding exit behavior under the conditional-exit design. Both exit rates by high-income individuals and the amounts of private purchases accord well with the theoretical predictions. In contrast, our results are not consistent with the prediction that, under universal-exit, support for public provision will unravel. High-income individuals in the universal-exit treatment did not exit as much as predicted; and conditional on many high-income individuals remaining in the public system, it was then rational for lower-income individuals to also remain (to benefit from the income redistribution carried out through public provision).

A key question is why high-income individuals failed to exit as predicted in the universalexit treatment but did exit largely as predicted under conditional-exit. Additional sessions using modified designs to test some specific conjectures regarding this unexpected behavior found that this exit behavior was not related to other-regarding preferences among subjects. Low rates of exit in the universal-exit treatment could have been due to the fact that this treatment presented the public system as the default option from which one had to actively choose to exit, and it was not obvious whether such exit was socially approved. In contrast, the conditional-exit treatment explicitly and uniquely gave high-income individuals the option to exit. Importantly, priming the universal-exit treatment with 10 periods of the conditional-exit treatment changed behavior: high-income individuals now recognized the value of exit, causing them to exit at higher rates, and once others recognized that the high income individuals were exiting they followed. Although this resulted in significantly more exit than in the unprimed universal-exit treatment, there were still individuals who could have, but did not exit. Even when holding incomes constant and providing full information 
regarding the income levels of those subjects who exited, subjects did not totally abandon the public system as predicted.

We also tested a version of the public-only, universal-exit and conditional-exit treatments using an explicit health care frame. In the health frame, for conditional exit we observed exit rates comparable to those in the non-health frame, but for the universal-exit treatment we observed exit rates higher than in the non-health frame. These higher exit rates under the health frame in the universal-exit treatment are more consistent with the predictions from our theoretical model. Our design did not allow us to identify what about the health care frame drove this result. This is an important question for future health-related experiments to investigate in greater detail. ${ }^{20}$

Our results have a number of potential policy implications pertaining to health care financing, health care consumption, and overall benefits. ${ }^{21}$ The results from our main design support the predictions for a public-only system of health care financing. If the individuals participating in this environment were given the opportunity to vote on replacing a privateonly health care system by a publicly financed system, the individuals in the three lower quintiles of the income distribution would be better off by replacing the private-only system. ${ }^{22}$ These results support what is typically expected from a policy that replaces private provision with tax-financed uniform public provision.

When universal-exit was offered to the individuals in the public-only environment, over half of the individuals in the top four quintiles chose to exit. This exit causes the level of public provision to fall and the amount available to the people in the lower three quintiles to be less than the amount of public provision available to them in the public-only system. ${ }^{23}$ When our universal-exit sessions were framed as health care an even larger percentage of individuals in the top four quintiles chose to exit, leading to an even greater reduction in publicly provided health care and health care consumption by the individuals in the lower

\footnotetext{
${ }^{20}$ It would also be interesting to compare exit behavior under health care frames with that for other sector frames, such as education.

${ }^{21}$ We draw these implications based on the results presented in Tables 6 and 7, which were obtained in the investment frame in which the collective good was not identified as health care. However, given the tax rates and exit rates observed subsequently in the health care frame, the implications carry over in a straightforward way to health care environments.

${ }^{22}$ As seen in Table 7.

${ }^{23}$ As shown in Table 6.
} 
three income quintiles. The only individuals who ultimately benefit from universal-exit compared to public-only are those in the highest-income quintile. This is also true under conditional exit, although those in the second highest income quintile are no worse off in this type of mixed financing system.

As only the individuals in the highest income quintile benefit by moving from a publiconly system to systems that include universal- or conditional-exit options, we would expect that neither of the exit environments would be preferred by a majority of individuals who had knowledge of all three environments. With experience in the conditional- and universal-exit environments, the individuals in the upper three quintiles would prefer a system of private health care to either of the exit environments. ${ }^{24}$

If majority-rule voting were the collective choice mechanism used to select among pure private finance, pure public finance, and mixed public and private financing with an exit option, then both theoretically and empirically purely publicly financed health care would be selected by a majority of individuals. To the extent that our environment captures the naturally occurring environment, the existence of a public financing system of health care with an exit option would not arise through majority-rule voting that is fully representative of the people in the environment.

Our findings also suggest a number of other useful directions for future research on mixed systems of health care finance. First, we used an income condition for the conditionalexit treatment. It would be interesting to see if the same pattern of results hold when an occupation condition is used instead, as is the case in some systems that allow exit. Second, it would be informative to run a design in which, rather than give people the opportunity to exit from a public system (which serves as the baseline), give them opportunity to enter into the collective provision of the private good from a baseline of pure private provision. And finally, future research should explore the impact of modified assumptions regarding, for example, differences in transaction costs between public and private consumption, differences in uncertainty associated with public provision compared to private consumption and the public provision of a private health care good with positive externalities (such as result from vaccinations against infectious diseases).

\footnotetext{
${ }^{24}$ Tables 6 and 7 provide predictions for a private-only system.
} 


\section{References}

[1] Ahlert, M., S. Felder, and B. Vogt (2012) 'Which patients do I treat? An experimental study with economists and physicians,' Health Economics Review 2(1), doi:10.1186/2191-1991-2-1.

[2] Alm, J. and S. Jacobson (2007) 'Using Laboratory Experiments in Public Economics,' National Tax Journal 55(1), 129-152.

[3] Bearse, P., B. Cardak, G. Glomm, and B. Ravikumar (2013) 'Why Do Education Vouchers Fail at the Ballot Box?' European Journal of Political Economy 32, 26-37.

[4] Black, D. (1948) 'On the Rationale of Group Decision-making', Journal of Political Economy 56, 23-34.

[5] Buckley, N., K. Cuff, J. Hurley, S. Mestelman, S. Thomas, and D. Cameron (2015) 'Support for Public Provision with Top-Up and Opt-Out: A Controlled Laboratory Experiment,' Journal of Economic Behavior and Organization 111, 177-196.

[6] Cohen-Zada D. and M. Justman (2003) 'The Political Economy of School Choice: Linking Theory and Evidence,' Journal of Urban Economics 54, 277-308.

[7] Dufwenberg, M., S. Gächter and H. Hennig-Schmidt (2011) 'The Framing of Games and the Psychology of Play,' Games and Economic Behavior 73(2), 459-478.

[8] Epple, D. and R. E. Romano (1996a) 'Public Provision of Private Goods,' The Journal of Political Economy 104(1), 57-84.

[9] Epple, D. and R. E. Romano (1996b) 'Ends Against the Middle: Determining Public Service Provision when there are Private Alternatives,' Journal of Public Economics 62, $297-325$.

[10] Fiorina, M. and C. Plott (1978) ' Committee Decisions under Majority Rule: An Experimental Study,' The American Political Science Review 72(2), 575-598. 
[11] Fischbacher, U. (1999) 'z-Tree ? Zurich Toolbox for Readymade Economic Experiments,'Institute for Empirical Research in Economics, University of Zurich, Working Paper 21.

[12] Glomm, G. and B. Ravikumar (1998) 'Opting Out of Publicly Provided Services: A Majority Voting Result,' Social Choice and Welfare 15, 187-99.

[13] Glomm, G., B. Ravikumar, and I. C. Schiopu (2011) 'The Political Economy of Education Funding' in E. Hanushek, S. Machin and L. Woessmann (eds.) Handbook of the Economics of Education, Volume 4 (Amsterdam: North-Holland), 615-680.

[14] Gouveia, M. (1997) 'Majority Rule and the Public Provision of a Private Good,' Public Choice 93, 221-224.

[15] Greiner, B (2015) 'Subject Pool Recruitment Procedures: Organizing Experiments with ORSEE,' Journal of the Economic Science Association 1, 114-125.

[16] Griesinger D. and J. Livingston (1973) 'Toward a Model of Interpersonal Motivation in Experimental Games,' Behavioral Science 18(3), 173-188.

[17] Harrison G. W. and J. A. List (2004) 'Field Experiments,' Journal of Economic Literature 42, 1009-1055.

[18] Hennig-Schmidt, H., R. Selten and D. Wiesen (2011) 'How Payment Systems Affect Physicians' Provision Behavior: An Experimental investigation,' Journal of Health Economics 30, 637-646.

[19] Kesternich, I., H. Schumacher, and J. Winter (2015) 'Professional norms and physician behavior: homo oeconomicus or homo hippocraticus?' Journal of Public Economics $131,1-11$.

[20] Kroll, S., T. Cherry, and J. Shogren (2007) 'Voting, Punishment and Public Goods,' Economic Inquiry 45(3), 557-570.

[21] Liebrand, W. (1984) 'The Effect of Social Motives, Communication and Group Size on behavior in an N-person Multi-stage Mixed-motive Game,' European Journal of Social Psychology 14(3), 239-264. 
[22] Mentzakis, E. and S. Mestelman (2013) 'Hypothetical Bias in Value Orientations Ring Games,' Economics Letters 120(3), 562-565.

[23] Margreiter, M., M. Sutter, D. Dittrich (2005) 'Individual and Collective Choice and Voting in Common Pool Resource Problems with Heterogeneous Actors,' Environmental and Resource Economics 32, 241-271.

[24] Moir, R. (1998) 'A Monte Carlo Analysis of Fisher Randomization Technique Reviving Randomization for Experimental Economics,' Experimental Economics 1, 87-100.

[25] Myers, G. and C. Lülfesmann (2009) 'On Opting Out of Public Services,' Simon Fraser University, mimeo.

[26] Norton, D. and R. M. Isaac (2010) 'The Role of Trust, Endogenous Institutions, and the Possibility of Grace in Public Good Provision,' Department of Economics, Florida State University, manuscript.

[27] Stiglitz, J.E. (1974) 'The Demand For Education in Public and Private School Systems,' Journal of Public Economics 3, 349-385.

[28] Sutter, M. and H. Weck-Hannemann (2003) 'On the Effects of Asymmetric and Endogenous Taxation in Experimental Public Goods Games,' Economic Letters 79, 59-67.

[29] van Dijk, E. and H. Wilke (2000) 'Decision-induced focusing in social dilemmas: givesome, keepsome, take-some, and leave-some dilemmas,' Journal of Personality and Social Psychology 78(1), 92-104.

[30] van Doorslaer, E. and T. Van Ourti. (2011) 'Measuring Inequality and Inequity in Health and Health Care.' In, S. Glied and P. Smith (Eds), The Oxford Handbook of Health Economics. Oxford: Oxford University Press, pp. 837-869. 


\section{Tables}

Table 1: Experimental Design

\begin{tabular}{|c|c|c|c|c|c|}
\hline \multicolumn{2}{|c|}{ Session Type } & $\begin{array}{l}\text { Treatment for } \\
\text { Periods } 1 \text { to } 10\end{array}$ & $\begin{array}{l}\text { Treatment for } \\
\text { Periods } 11 \text { to } 20\end{array}$ & Session Notes & $\begin{array}{l}\text { Number of } \\
\text { Subjects }\end{array}$ \\
\hline \multirow{4}{*}{ Main Design } & 1 & Public-Only & Universal-Exit & Neutral framing & 25 \\
\hline & 2 & Universal-Exit & Public-Only & Neutral framing & 25 \\
\hline & 3 & Public-Only & Conditional-Exit & Neutral framing & 25 \\
\hline & 4 & Conditional-Exit & Public-Only & Neutral framing & 25 \\
\hline \multirow{5}{*}{$\begin{array}{l}\text { Sensitivity } \\
\text { Analysis }\end{array}$} & 5 & Conditional-Exit & Universal-Exit & Neutral framing & 30 \\
\hline & 6 & Public-Only & Universal-Exit & $\begin{array}{l}\text { Neutral framing, } \\
\text { Constant incomes }\end{array}$ & 30 \\
\hline & 7 & Public-Only & Universal-Exit & $\begin{array}{l}\text { Neutral framing, } \\
\text { Constant incomes, } \\
\text { Told who exited }\end{array}$ & 30 \\
\hline & 8 & Public-Only & Universal-Exit & Health framing & 25 \\
\hline & 9 & Public-Only & Conditional-Exit & Health framing & 25 \\
\hline
\end{tabular}

Table 2: Exit and Private Purchases Decisions, Universal-Exit Treatment

\begin{tabular}{rlllll}
\cline { 2 - 3 } \cline { 5 - 6 } Income & $\begin{array}{l}\text { Percentage } \\
\text { of Exits }\end{array}$ & $\begin{array}{l}\text { Private } \\
\text { Purchases, L } \$\end{array}$ & & $\begin{array}{l}\text { Percentage } \\
\text { of Exits }\end{array}$ & $\begin{array}{l}\text { Mean Private } \\
\text { Purchases, L\$ }\end{array}$ \\
\hline 125 & n/a & 69.96 & & $8 \%$ & 82 \\
275 & $100 \%$ & 153.8 & & $16 \%^{*}$ & 171.13 \\
640 & $100 \%$ & 357.94 & & $56 \%^{*}$ & 358.29 \\
700 & $100 \%$ & 391.5 & & $72 \%^{*}$ & 370.57 \\
1500 & $100 \%$ & 838.93 & & $76 \%^{*}$ & 793.29 \\
\hline
\end{tabular}

Notes: ${ }^{*}$ indicates that the observed value is statistically significantly different from its predicted value at the $10 \%$ level of significance. 
Table 3: Exit and Private Purchases Decisions, Conditional-Exit Treatment

\begin{tabular}{rlllll}
\cline { 2 - 3 } & \multicolumn{2}{c}{ Predicted } & & \multicolumn{2}{c}{ Observed } \\
\cline { 2 - 3 } \cline { 5 - 6 } Income & $\begin{array}{l}\text { Percentage } \\
\text { of Exits }\end{array}$ & $\begin{array}{l}\text { Private } \\
\text { Purchases, L\$ }\end{array}$ & & $\begin{array}{l}\text { Percentage } \\
\text { of Exits }\end{array}$ & $\begin{array}{l}\text { Mean Private } \\
\text { Purchases, L\$ }\end{array}$ \\
\hline 700 & $100 \%$ & 391.5 & $94 \%^{*}$ & $361.47^{*}$ \\
1500 & $100 \%$ & 838.93 & & $94 \%^{*}$ & $752.68^{*}$ \\
\hline
\end{tabular}

Notes: See notes for Table 2.

Table 4: Mean Preferred Tax Rates by Income and Treatment

\begin{tabular}{|c|c|c|c|c|c|c|}
\hline \multirow[b]{2}{*}{ Income } & \multicolumn{2}{|c|}{ Predicted Rates } & \multicolumn{4}{|c|}{ Observed Mean Rates } \\
\hline & Public-Only & $\begin{array}{l}\text { Conditional- } \\
\text { Exit }\end{array}$ & $\begin{array}{l}\text { Public-Only } \\
\text { w/ Univ Exit }\end{array}$ & $\begin{array}{l}\text { Universal- } \\
\text { Exit }\end{array}$ & $\begin{array}{l}\text { Public-Only } \\
\text { w/ Cond Exit }\end{array}$ & $\begin{array}{l}\text { Conditional- } \\
\text { Exit }\end{array}$ \\
\hline 125 & 0.937 & 0.854 & $0.856^{*}$ & 0.809 & $0.857^{*}$ & $0.821^{*}$ \\
\hline 275 & 0.821 & 0.642 & $0.776^{U, *}$ & $0.680^{P}$ & $0.761^{C, *}$ & $0.660^{P}$ \\
\hline 640 & 0.564 & 0.336 & 0.545 & $0.474^{C}$ & $0.549^{C}$ & $0.383^{P, U, *}$ \\
\hline 700 & 0.531 & $\mathrm{n} / \mathrm{a}$ & $0.527^{*}$ & 0.509 & $0.507^{*}$ & 0.627 \\
\hline 1500 & 0.265 & $\mathrm{n} / \mathrm{a}$ & $0.288^{U, *}$ & $0.426^{P, C}$ & 0.292 & $0.750^{U}$ \\
\hline
\end{tabular}

Notes: All statistical tests are conducted using a $10 \%$ significance level. ${ }^{*}$ indicates that the observed value is significantly different from its predicted value. ${ }^{P}$ denotes a statistically significant difference between the universal-exit or conditional-exit value and associated public-only value. ${ }^{U(C)}$ denotes a statistically significant difference between the treatment value to which the superscript is attached and the corresponding observed universal-exit (conditional-exit) value. There are 20 observations for the public-only treatment for all endowment levels. There are 10,10,8,8 and 7 observations for the universal-exit treatment endowments of $125,275,640,700$ and 1500 , respectively and 10,10,10,3 and 3 observations for the conditional-exit treatment endowments of 125, 275, 640, 700 and 1500, respectively. The mean observed preferred tax rate of the highest-income subject in the exit treatment (0.426) is significantly different from the mean observed preferred rate of the highest-income subject in the conditional-exit treatment (0.750) using a t-test, but is not significantly different using a Mann-Whitney test. 
Table 5: Mean Implemented Tax Rates by Treatment

\begin{tabular}{rcccc}
\hline & $\begin{array}{c}\text { Public-Only } \\
(\mathrm{w} / \text { Universal-Exit })\end{array}$ & $\begin{array}{c}\text { Universal- } \\
\text { Exit }\end{array}$ & $\begin{array}{c}\text { Public-Only } \\
(\mathrm{w} / \text { Conditional-Exit })\end{array}$ & $\begin{array}{c}\text { Conditional- } \\
\text { Exit }\end{array}$ \\
\hline Predicted Rate & 0.564 & $\mathrm{n} / \mathrm{a}$ & 0.564 & 0.642 \\
Observed Mean & & & & \\
Implemented Rate & $0.559^{U}$ & $0.664^{P}$ & $0.562^{C}$ & $0.655^{P}$ \\
(Std Dev) & $(0.028)$ & $(0.046)$ & $(0.019)$ & $(0.043)$ \\
Observations & 10 & 10 & 10 & 10 \\
\hline
\end{tabular}

Notes: See notes for Table 4. In the universal-exit treatment, the individual with endowment of 125 will be indifferent between exiting or remaining in the public system. In the case when the individual does not exit, the individual's preferred tax rate is 0.559 . The observed mean implemented tax rate of 0.664 in the universal-exit treatment is significantly different from this value. 


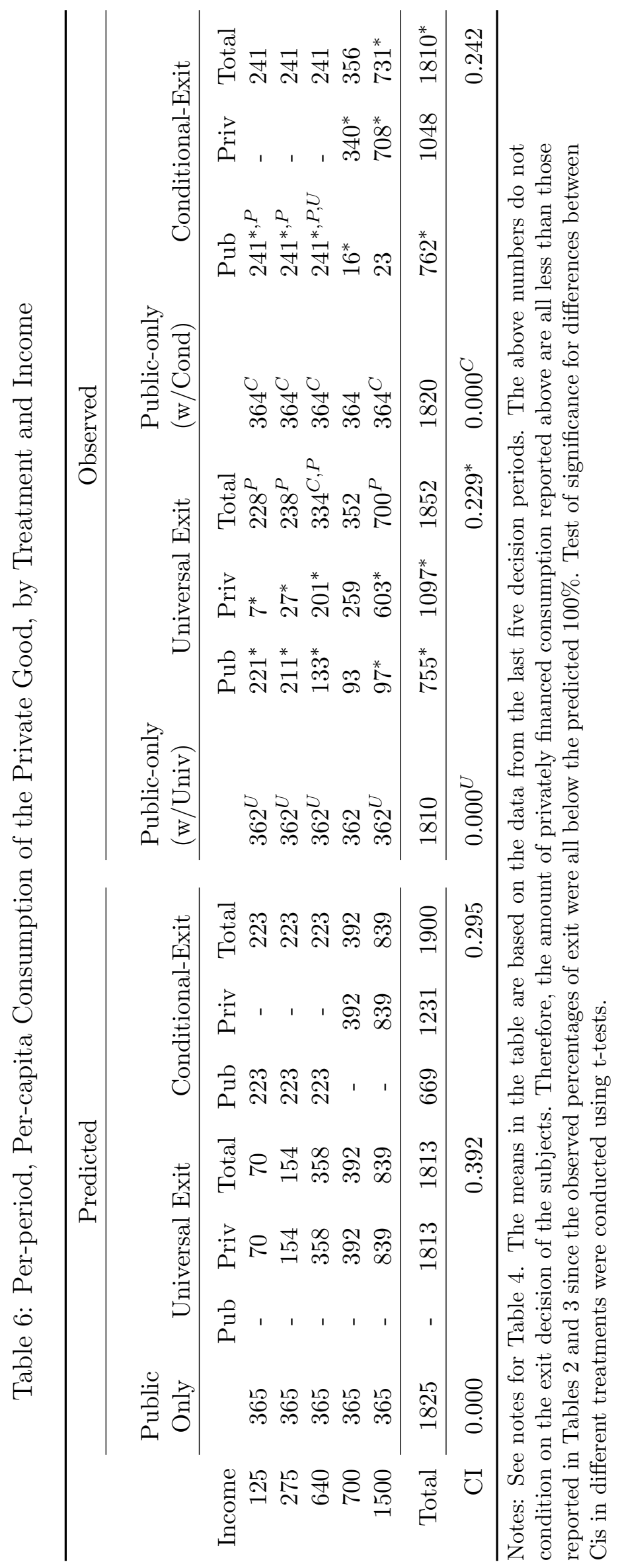




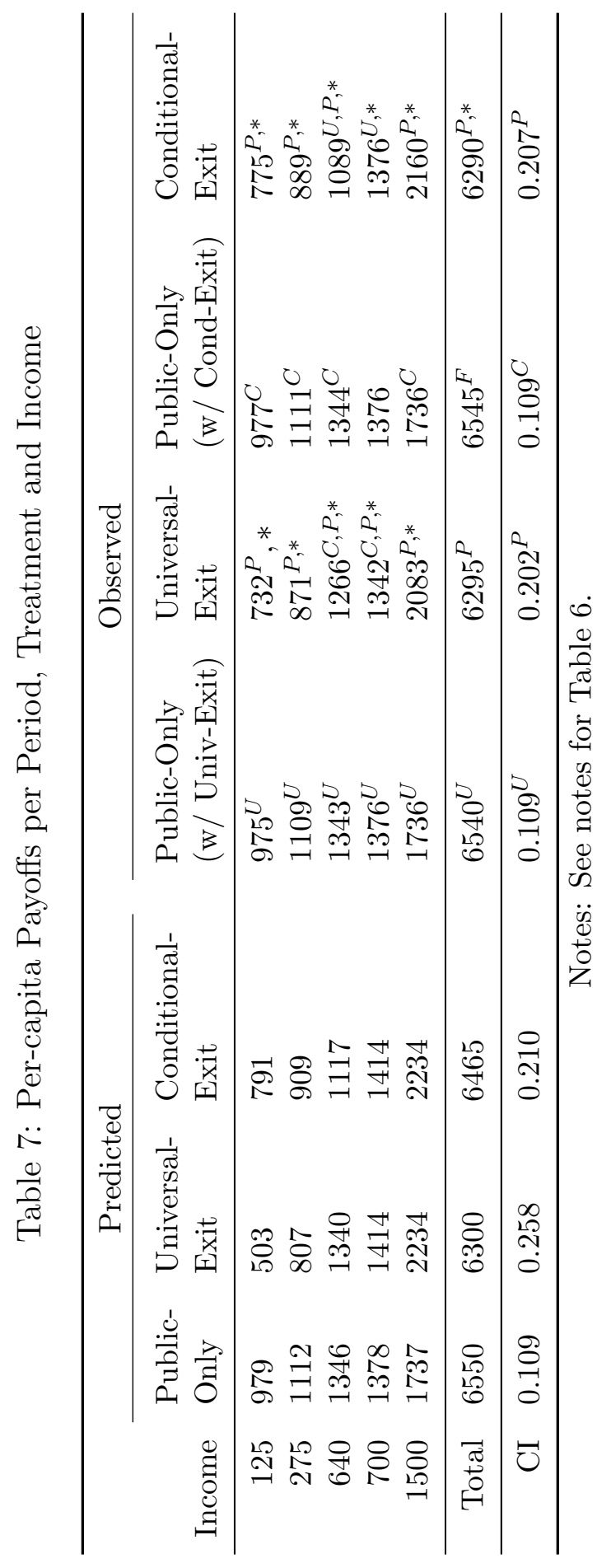


Table 8: Observed Percentage (Frequency) of Exits per period by Treatment and Income

\begin{tabular}{|c|c|c|c|c|c|}
\hline Income & $\begin{array}{l}\text { (1) } \\
\text { Conditional- } \\
\text { Exit }\end{array}$ & $\begin{array}{l}\text { (2) } \\
\text { Universal- } \\
\text { Exit }\end{array}$ & $\begin{array}{l}\text { (3) } \\
\text { Universal-Exit } \\
\text { following } \\
\text { Conditional-Exit }\end{array}$ & $\begin{array}{l}(4) \\
\text { Universal-Exit } \\
\text { with } \\
\text { Constant Incomes }\end{array}$ & $\begin{array}{l}(5) \\
\text { Universal-Exit } \\
\text { Constant Incomes } \\
\text { Told Who Exited }\end{array}$ \\
\hline 125 & $0 \%(0)$ & $8 \%(4)$ & $16 \%(5)$ & $7 \%(2)$ & $24 \%(7)$ \\
\hline 275 & $0 \%(0)$ & $16 \%(8)$ & $60 \%$ * (18) & $50 \% \star(15)$ & $69 \%(20)$ \\
\hline 640 & $0 \%(0)$ & $56 \%(28)$ & $80 \%$ * (24) & $80 \%$ * $(24)$ & $72 \%(21)$ \\
\hline 700 & $88 \%(70)$ & $72 \%^{\gamma}(36)$ & $87 \%^{\$}(26)$ & $80 \%(24)$ & $86 \%(25)$ \\
\hline 1500 & $96 \%(77)$ & $76 \%^{\gamma}(38)$ & $93 \% \star \$,(28)$ & $100 \% \star \$,(30)$ & $97 \% \$(28)$ \\
\hline $\mathrm{N}$ & 80 & 50 & 30 & 30 & 29 \\
\hline
\end{tabular}

Note: $\mathrm{N}$ indicates the number of observations per income value for each treatment. ${ }^{\gamma}$ indicate that the percentage of exits for the two highest income levels is significantly different from the percent of exits in Column (1) at the $10 \%$ significance level. ${ }^{\star}$ indicates the percentage of exits in Column (3) and in Column (4) that are significantly different from the percent of exits in Column (2) at the $10 \%$ significance level. None of the observed frequencies in Columns (3) and (4) and in Columns (4) and (5) are significantly different from each other at a $10 \%$ significance level. All tests are t-tests computed using a clustered probit regression model for each income value in which an exit dummy is regressed on the full set of treatment dummies and errors are assumed to be clustered at the session level to account for correlation among exit decisions made over time and across subjects within the same session. Finally, ${ }^{\$}$ indicates that the percentage of exits is not significantly different from $100 \%$ at the $10 \%$ significant level using a chi-square test. 
Table 9: Mean Exit, Private Purchase and Implemented Tax Rate Decisions for Health Frame Treatments

\begin{tabular}{|c|c|c|c|c|}
\hline \multirow[b]{2}{*}{ Income } & \multicolumn{2}{|c|}{ Universal-Exit Health Frame } & \multicolumn{2}{|c|}{ Conditional-Exit Health Frame } \\
\hline & $\begin{array}{l}\text { Observed } \\
\text { Percentage of } \\
\text { Exits }\end{array}$ & $\begin{array}{l}\text { Observed Mean } \\
\text { Private } \\
\text { Purchases, L\$ }\end{array}$ & $\begin{array}{l}\text { Observed } \\
\text { Percentage of } \\
\text { Exits }\end{array}$ & $\begin{array}{l}\text { Observed Mean } \\
\text { Private } \\
\text { Purchases, L\$ }\end{array}$ \\
\hline 125 & 0.16 & 70.17 & - & - \\
\hline 275 & $48 \% *$ & 150.70 & - & - \\
\hline 640 & $92 \% *$ & 346.33 & - & - \\
\hline 700 & $92 \% *$ & 379.88 & 0.88 & 332.05 \\
\hline \multirow[t]{2}{*}{1500} & $92 \% *$ & 794.79 & 0.96 & 692.98 \\
\hline & $\begin{array}{l}\text { Public-Only } \\
\text { (w/ Universal- } \\
\text {-Exit }\end{array}$ & Universal-Exit & $\begin{array}{l}\text { Public-Only } \\
\text { (w/ Conditional- } \\
\text { Exit) }\end{array}$ & $\begin{array}{l}\text { Conditional- } \\
\text { Exit }\end{array}$ \\
\hline $\begin{array}{r}\text { Observed Mean } \\
\text { Implemented Tax } \\
\text { Rate }\end{array}$ & 0.552 & 0.645 & $0.483^{*}$ & $0.5512^{*}$ \\
\hline
\end{tabular}

Notes: * indicates that the observed value is statistically significantly different from its counterpart value in the neutrally framed treatments at the $10 \%$ level of significance. 